\title{
Lipid R1 MRI
}

National Cancer Institute

\section{Source}

National Cancer Institute. Lipid R1 MRI. NCI Thesaurus. Code C122668.

An imaging method for the mapping of oxygen in tissues. It is based on higher solubility of oxygen in lipids than in water. By monitoring changes in the R1 relaxation rate of the lipid peak rather than those of water, estimates of variations in tissue oxygenation are obtained. 